\title{
Structural Behavior of Novel ECC Short Columns Subjected to Eccentric Loading
}

\author{
Safaa mashshay ${ }^{a}$, Adnan Al-Sibahya ${ }^{a_{*}}$ \\ ${ }^{a}$ Civil Engineering Department, College of Engineering, The University of Al-Qadisiyah, Iraq.
}

\section{ARTICLE INFO}

\section{Article history:}

Received 05 October 2019

Received in revised form 16 January 2020

Accepted 28 January 2020

\section{Keywords:}

ECC columns

hybrid ECC

eccentric columns

\begin{abstract}
A B S T R A C T
This study was undertaken in order to investigate the structural behaviour of novel Engineering Cementitious Composites (ECC) columns subjected to eccentric loading. These columns were experimentally formulated using a hybridization of steel and polypropylene fibres. Two ratios were adopted for the steel fibres of $0.5 \%$ and $1 \%$, whilst the polypropylene fibre was kept to be constant at a ratio of $0.5 \%$ for all of the ECC columns. The eccentric loads were applied at two eccentricities: small (h/6) and large (5h/12). A comparison was also made with the behaviour of self-compacting concrete and traditional ECC columns containing either steel or polypropylene fibres. The vertical and lateral deformations as well as the maximum load at failure were noted. The results obtained showed that the hybrid ECC columns exhibited higher load carrying capacities when compared with those of both self-compacting concrete and traditional ECC columns. The percentage increase was $30 \%$. The hybrid ECC column samples containing $1 \%$ steel fibre did not show a signification difference in the load-deformation behaviour when it compared with that containing $0.5 \%$ steel fibre. The values of eccentricity governed the global behaviour of the tested columns. The predicated load carrying capacity of the ECC columns needs a magnification factor in case of concentric test, and to take into account the existence of fibres ratio when calculating the area of steel reinforcement for eccentric loading.
\end{abstract}

(C) 2020 University of Al-Qadisiyah. All rights reserved.

\section{Introduction}

Developing the behaviour of structural members is the main concern for the most of the published research works in the construction field nowadays. In general, such developing can be obtained either through improving the composition of these members or by updating the implementation techniques used. Reinforced columns are part of these structural members which generally referred to as compression members [1]. In some cases, columns may carry bending moments about one or both axes of the cross section. The general behaviour of columns is governed by the amount of steel. Reinforcement available for both longitudinal and transverse directions, the strength of the concrete used, conditions of the supports and the slenderness ratio [2]. Depending on the nature of the imposed load, the failure modes of the reinforced concrete columns are in the forms of crushing, shearing and bending for the loading cases of concentric, transverse and eccentric, respectively [3-5]. A combined failure modes may also be found for the same case.

Several previous studies were carried out for enhancing the integrity of the reinforced concrete columns under various conditions of loading. In the last decade, there was a tendency for replacing the conventional concrete with Engineering Cementitious Composites (ECC) [6-15]. However, it's used in column elements is less than that for flexural structural members [11]. Except for the absent of coarse aggregate, this material has a similar constituents as for the fiber reinforced concrete (FRC). Nevertheless, ECC usually exhibits strainhardening after the propagation of the first crack rather than of the usual tension-

* Corresponding author.

E-mail address: Adnan.alsibahy@qu.edu.iq (Adnan Al-Sibahy ) 
softening [6]. Although the desired advantages of ECC mentioned above, improving its properties still needs for investigation. Since there is no published research work about using hybrid fibers in ECC, so it is necessary to undertake such trend into consideration. In this paper, using hybrid steel and polypropylene fibers at different ratios in the formulation of reinforced column members has been experimentally investigated. These columns were tested under the actions of eccentric loading. A comparison was also made with the traditional ECC containing either steel or polypropylene fibers as well as with the behaviour of reinforced self-compacting concrete columns. Some expressions were suggested to identify the general behaviour under the test conditions.

\section{Experimental Work}

\subsection{Materials used}

An ordinary Portland cement by Lafarge Company was used in this study. It was compliant with EN BS 197-1 [16]. Locally available natural sand from Al-Najaf quarries was used as a fine aggregate to produce both of the ECC and self-compacting concrete specimens. It has a maximum particle size of 4.75 $\mathrm{mm}$. On the other hand, crushed gravel with a maximum size of $10 \mathrm{~mm}$ was used as a coarse aggregate to produce the self-compacting concrete specimens only. It was provided from Al-Nibaei quarry. Both types of aggregate are consistent with the grading limits of EN BS 882.1992 [17] and they have sulphate contents of $0.216 \%$ and $0.082 \%$, respectively. A limestone powder was used as a filler in preparing of the self-compacting concrete columns, while silica fume was used in producing of ECC columns. For all of the column samples, the Daracem SP6 superplasticizer admixture of the sulphonated naphthalene formaldehyde condensate SNF [18] was used, its maximum chloride and alkali contents were $<0.1 \%$ and $0.5 \%$ by mass, respectively. Two types of fibres were used, namely steel and polypropylene fibres. They were incorporated in the ECC column samples in different ratios as a percentage from the total volume of the mixture. The aspect ratios of the steel and polypropylene fibres were 65 and 375, respectively. Two different sizes of deformed steel bars of $\varnothing 10$ and $\varnothing 12$ were used in all of the column samples as the transverse and main reinforcements, respectively. The values of the yield and ultimate strength of the former steel bars were $480 \mathrm{MPa}$ and $700 \mathrm{MPa}$, respectively.

\subsection{Selection of the concrete mix}

For the purpose of comparison, a self-compacting concrete was selected as a reference mix. The reason for that is the ECC usually has high flowability and its need for compaction effort is usually minimal [15]. On this basis, the composition of the reference mix was selected to be in the strength level of 50 MPa at 28 days. This in turn gives a mix proportion of 1:1.5:1.6 with cement content and w/c ratio of $430 \mathrm{~kg} / \mathrm{m}^{3}$ and 0.42 , respectively. Both of limestone and superplasticizer were used in this mix with ratios of $0.2 \%$ and $1.5 \%$, respectively. On the other hand, the suggested mix proportion of cement: 1, silica fume: 0.22 , sand: 2 , w/c : $38 \%$ by volume was selected for ECC. This employ $570 \mathrm{~kg} / \mathrm{m}^{3}$ cement, $1140 \mathrm{~kg} / \mathrm{m}^{3}$ sand and $124 \mathrm{~kg} / \mathrm{m}^{3}$ silica fume. Two groups of the hybrid fibres were used in the ECC ; the first incorporated $0.5 \%$ steel and $0.5 \%$ polypropylene fibres, and the second incorporated $1 \%$ steel and $0.5 \%$ polypropylene fibres. The former fibre percentages were recommended by previous studies $[1,5]$.

\subsection{Description of the tested samples}

The experimental programme comprised of testing eight column samples. All of the tested columns were square in shape. The height of columns was selected to be $1200 \mathrm{~mm}$. The column samples with a square cross section of $200 * 200 \mathrm{~mm}$. This in turn gives a slenderness ratio of 20 . A minimum steel area $($ As $\geqslant 1 \%)$ was used for reinforcing the longitudinal direction, namely $4 \varnothing 12 \mathrm{~mm}$. Whereas, 12 stirrups were adopted using Ø10@100mm c/c as a reinforcement for the transverse direction. The calculations for both of the former reinforcements was based upon the requirement of ACI 318M-11 Code [19]. In order to avoid the concentration of stresses near the loading plate, the upper and lower parts of the columns were expanded to be in a tapered shape. Same technique was also used by [15]. Figure 1 shows the details of the tested columns.
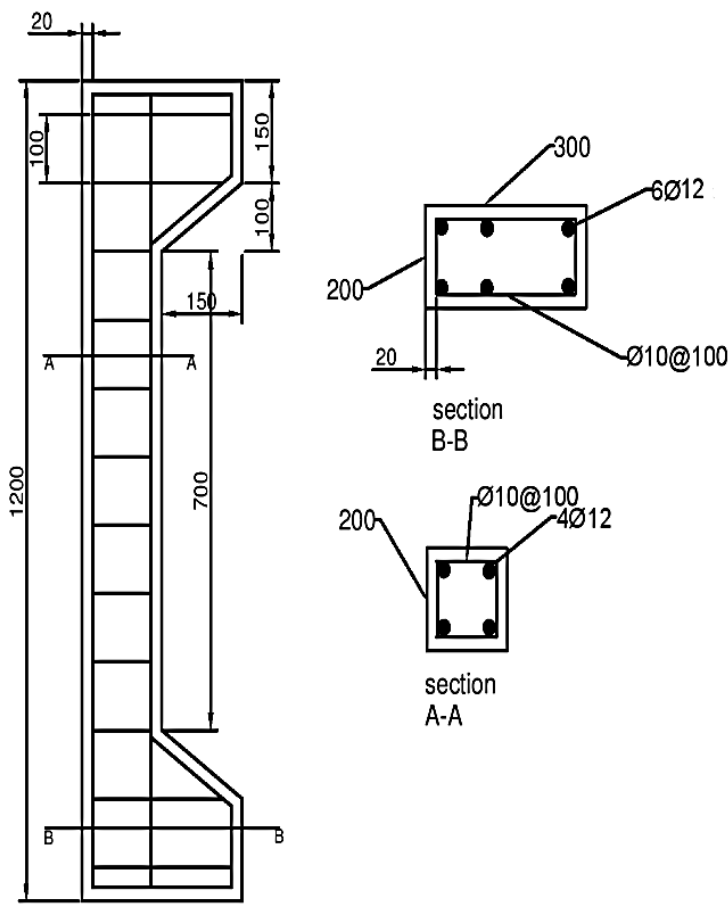

B-B

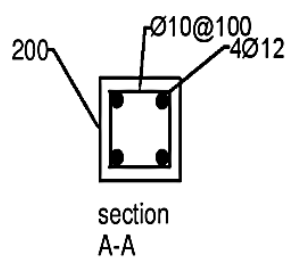

Figure 1. Details of the tested columns

\subsection{Mixing, casting, curing operations and the tested parameters}

As shown in Figure 2, for all of the column samples, the mixing, casting and curing operations were carried out based upon the procedure suggested by BS EN 12390-2 (BSI, 2009c) [20]. Before running the test, all of the column samples were capped using rapid cement mortar, then they were painted in a white colour. During the lifting process, the location of columns was centrally adjusted with the centre line of the testing machine. In order to achieve the objective of this study, the nature of the applied load was in two categories; namely small $(1 / 6 \mathrm{~h})$ and large $(5 / 12 \mathrm{~h})$. The tested columns were designated based on the type of column, nature of loading and type and ratio of the fibre used, as illustrated in Table 1. The applied load was manually controlled and a loading rate of $0.5 \mathrm{MPa} / \mathrm{Sec}$ was adopted. During running of the test, both vertical and lateral deformations were measured using LVDT at the top and mid-height of the column. For each column, the test was performed until failure and the load-crack history was recorded. In addition, the failure mode and critical zones were monitored for each case. 
Table 1. The designation of the tested columns with their parameters

\begin{tabular}{lllllll}
\hline No.Sample & $\begin{array}{l}\text { Type of } \\
\text { column }\end{array}$ & $\begin{array}{l}\text { Cross } \\
\text { section mm }\end{array}$ & e/r & $\begin{array}{l}\text { Steel fibre } \\
\text { Ratio\% }\end{array}$ & $\begin{array}{l}\text { Polypropylene } \\
\text { fibre \% }\end{array}$ \\
\hline 1 & EBe1-0.5S-0.5P & $200 * 200$ & 0.4 & 0.5 & 0.5 \\
2 & EBe2-0.5S-0.5P & & $200 * 200$ & 0.93 & 0.5 & 0.5 \\
3 & EBe1-1S-0.5P & ECC & $200 * 200$ & 0.4 & 1 & 0.5 \\
4 & EBe2-1S-0.5P & & $200 * 200$ & 0.93 & 1 & 0.5 \\
5 & EBe2-0S-0.5P & & $200 * 200$ & 0.93 & 0 & 0.5 \\
6 & EBe2-1S-0P & & $200 * 200$ & 0.93 & 1 & 0 \\
7 & CBe1 & CC & $200 * 200$ & 0.4 & 0 & 0 \\
8 & CBe2 & $200 * 200$ & 0.93 & 0 & 0 \\
\hline
\end{tabular}

\section{Results and discussions}

The results obtained for the load-deformation relationships for various column samples are shown in Figures 3 to 8. A superior behaviour was noted for the hybrid ECC columns in terms of deformation and load carrying capacity aspects compared with those containing self-compacting concrete and those of the traditional ECC. For the concrete and hybrid ECC columns subjected to eccentric load of $\mathrm{h} / 6$, the results obtained are presented in Figures 3and 4. Both of hybrid ECC columns reached the level of $1400 \mathrm{kN}$ load carrying capacity with a notable increase for the sample containing $1 \%$ steel fibre. On the other hand, the concrete column (CBe1) exhibited a lower failure load at $1070 \mathrm{kN}$. This in turn gives percentage increase of $30 \%$ for the hybrid ECC columns .Identical shape for the load-deformation curve in both directions was observed. The end values of vertical deformations for the columns samples of concrete, hybrid ECC with $0.5 \%$ steel fibre and that of $1 \%$ steel fibre were $5 \mathrm{~mm}, 9 \mathrm{~mm}$ and $13 \mathrm{~mm}$, respectively. The corresponding values for the lateral deformations were $5 \mathrm{~mm}, 12 \mathrm{~mm}$ and $17 \mathrm{~mm}$, respectively. Figures 5 to 8 show a detail comparison for all of the tested columns subjected to eccentric load of $5 \mathrm{~h} / 12$ in terms of load-vertical and lateral deformations, respectively. The role of steel fibre was clear regarding improving the load carrying capacity feature. The traditional ECC column with $1 \%$ steel fibre exhibited the highest strength capacity at failure load at $925 \mathrm{kN}$. If the polypropylene fibre is used the aforementioned strength capacity will be reduced. This could be explained by two issues: the first is related to the lower strength capacity of the polypropylene fibre itself in both compression and tension aspects when compared with those for steel fibre; and the second, is related to the present of such kind of fibre leads to the formation of entrapped voids within the ECC composition which represents a weakness point that results in reducing the final strength of the column sample. This behaviour was clearly shown for the column containing polypropylene fibre alone, in which the load-bearing capacity reached $750 \mathrm{kN}$, meaning $20 \%$ percentage reduction compared with that of steel fibre. If combination of both fibres is used as in the EBe2-1 S-0.5 P and EBe2-0.5 S-0.5 $P$ columns, the load carrying capacity will increase with a percentage equivalent to the added ratio of steel fibre. In general, all of the column samples incorporating fibres showed vertical deformation of $11 \mathrm{~mm}$ with a parentage increase of 50\% compared with that of concrete column. Similar attitude was also noted for the lateral deformation recorded at the mid height of the column. However, the column formulated with polypropylene fibre alone revealed the highest lateral deformation due to its capability to reduce the width of cracks. Consequently, higher lateral buckling can be achieved prior to the column failure. The hybrid columns have more lateral ductile behaviour than that containing steel fibre alone. The percentages increase in the value of lateral deformation for the EBe2-0 S-0.5 P, EBe2-0.5 S-0.5 P, EBe2-1 S-0.5 P and EBe2-1 S-0 P compared with that of concrete sample were 127\%, 171\%, 180\% and $116 \%$, respectively.

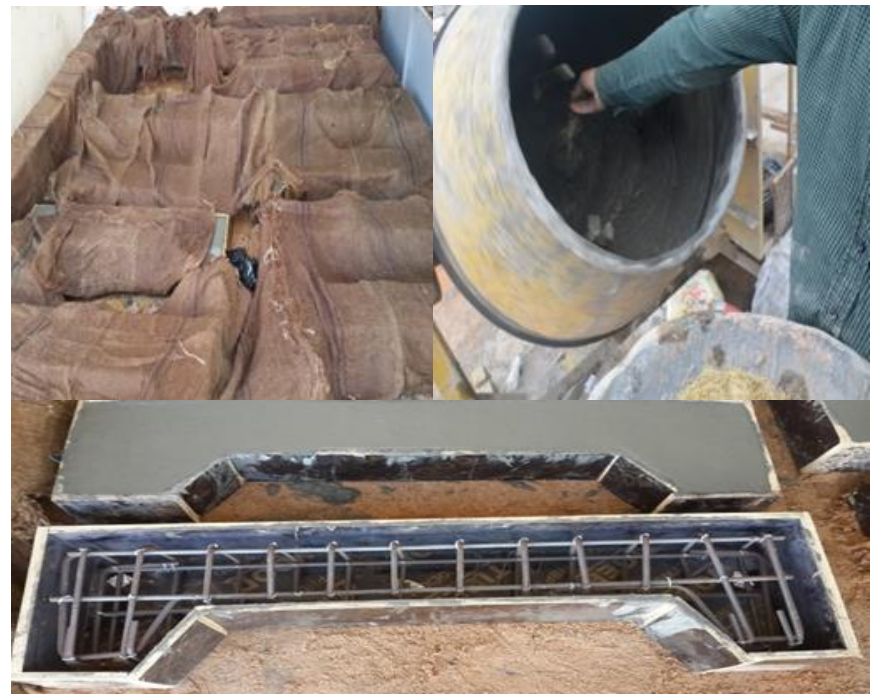

Figure 2: Preparation of moulds, mixing and curing operations

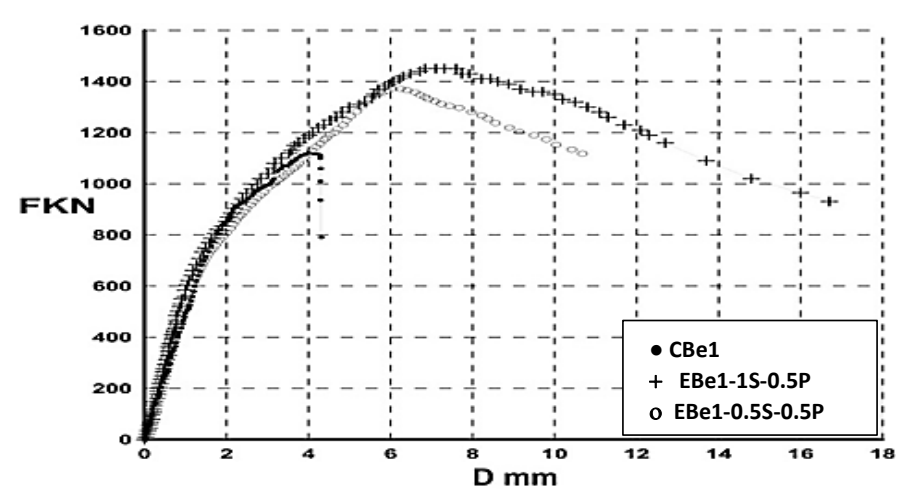

Figure 3: Load-lateral deformation of columns subjected to eccentric load of $h / 6$

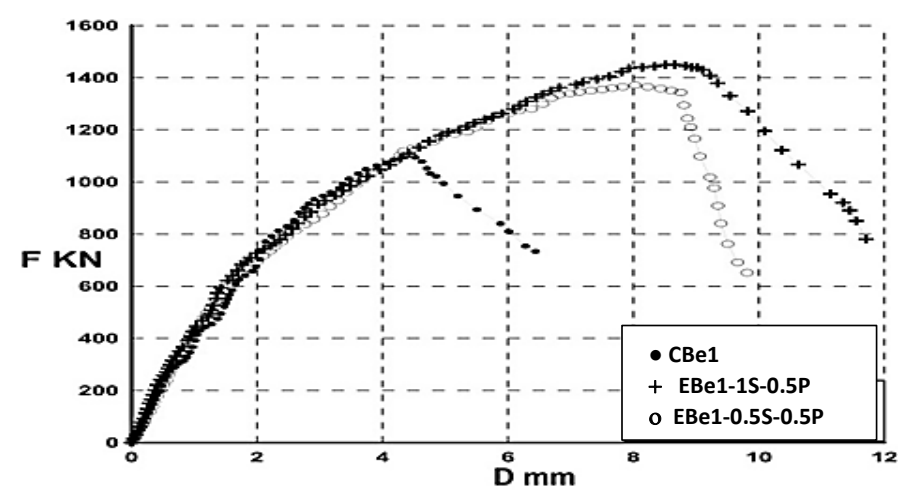

Figure 4: Load-vertical deformation of columns subjected to eccentric load of $h / 6$ 


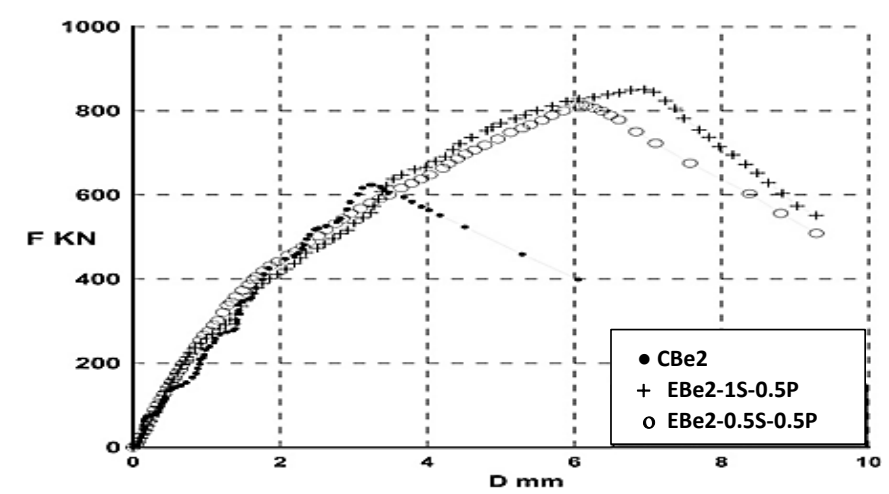

Figure 5: Load-vertical deformation of columns subjected to eccentric load of $5 \mathrm{~h} / 12$

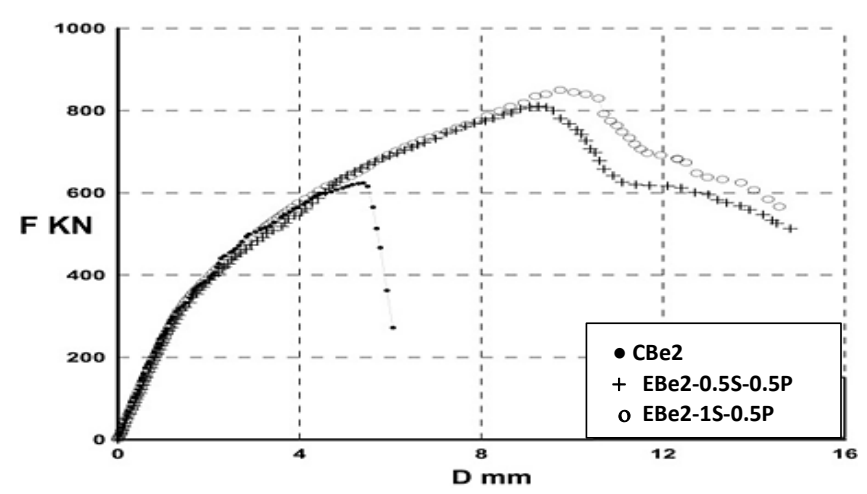

Figure 6: Load-lateral deformation of columns subjected to eccentric load of $5 \mathrm{~h} / 12$

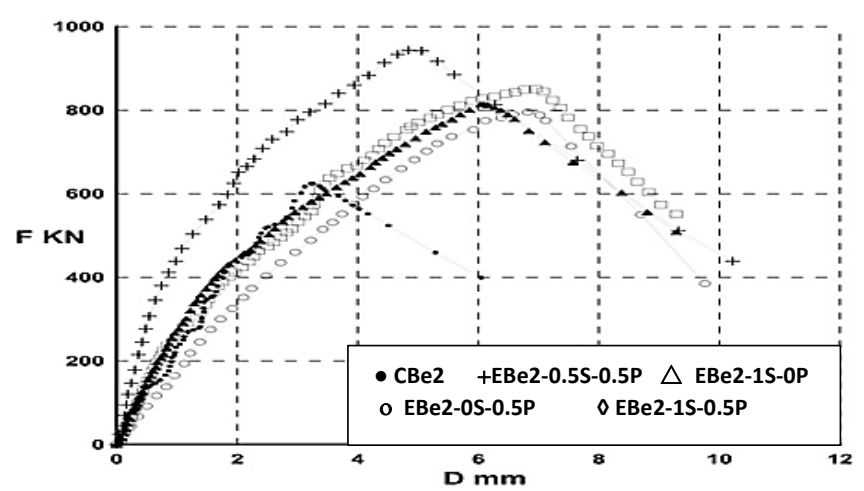

Figure 7: Load-vertical deformation for various types of columns subjected to eccentric load of $5 \mathrm{~h} / 12$

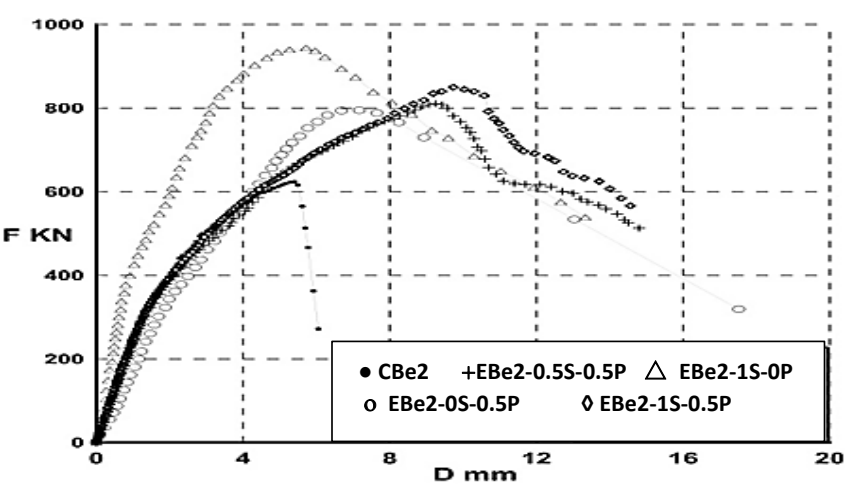

Figure 8: Load-lateral deformation for various types of columns subjected to eccentric load of $5 \mathrm{~h} / 12$
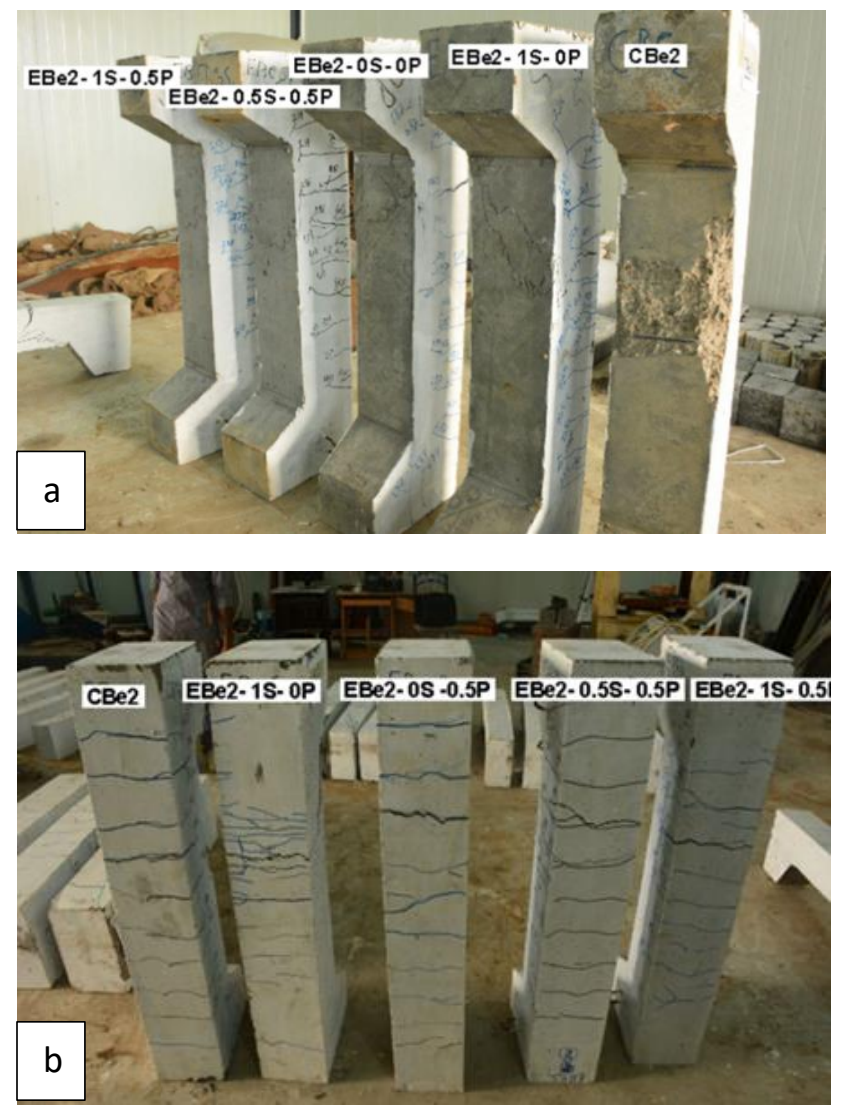

Figure 9: Failure modes for the columns under eccentric loading 5h/12; (a) front view, (b) back view 
For the eccentric loading, composite failure modes of compression and bending were noted for both of hybrid ECC columns, as shown in Figure 9a and b. Multi cracks were located underneath the tapered part and at the mid height of the column which explain the role of the fibres in controlling the global failure. More cracks along the column height were noted for all of the ECC samples compared with that of concrete sample (CBe2). This is indicative for less spacing of cracks which can be achieved when the steel and/or polypropylene fibres are used. Spalling behaviour was also observed for the concrete column sample.

Based upon the preliminary mechanical strength testes performed on the concrete, traditional ECC and hybrid ECC cube samples, the results of the compressive strength values are shown in Table 2.

Table 2. The values of compressive strengths for different composition of columns at 28 days age

\begin{tabular}{llll}
\hline No. & Symbol & $\begin{array}{l}\text { Cube } \\
\text { compressive } \\
\text { strength } \\
\text { (MPa) }\end{array}$ & $\begin{array}{l}\text { Equivalent cylinder } \\
\text { compressive strength } \\
\text { (MPa) }\end{array}$ \\
\cline { 2 - 4 } 1 & CC & 59.6 & 70.1 \\
2 & ECC-0.5 S-0.5 P & 53.9 & 63.4 \\
3 & ECC-1 S-0.5 P & 56.3 & 66.2 \\
4 & ECC-1 S-0 P & 62.6 & 73.6 \\
5 & ECC-0 S-0.5 P & 50.4 & 59.3 \\
\hline
\end{tabular}

For the case of biaxial bending, Bresler [2] suggested reciprocal method to predict the load carrying capacity for the eccentric loading, as in Eq. 1

Table 3. The calculated and measured results of load carrying capacity for the eccentric loaded columns means increasing the area of steel reinforcement in an equivalent percentage to that of the fibre used. Such modification was only applied in calculation of the load carrying capacity of the ECC columns and the results obtained are shown in Table 3. Close agreement has been achieved with respect to the experimental measurements.

\section{Conclusions}

This study is an attempt to produce a new formulation of ECC columns throughout hybridization process using both steel and polypropylene fibers followed by a structural evaluation for their behaviour under eccentric loading. The main significant findings of this study can be summarized as follows:

1- Higher load carrying capacities were observed for the hybrid ECC columns compared with those of self-compacting concrete under eccentric loading scenarios.

2- Both of the hybrid ECC columns behaved in a similar manner in terms of load-deformation criteria with slight increase in the value of lateral deformation noted when $1 \%$ of steel fibre is used.

3- The role of steel fibre was demonstrated in preventing the propagation of cracks, whilst polypropylene fibre works on minimizing the crack width.

4- The maximum load at failure was clearly reduced with an increase in the value of eccentricity. The percentage of decrease reached about $45 \%$.

5- In case of eccentric loading, the predicted values of load carrying capacities for ECC columns the fiber ratio should be taken in consideration in order to compute the maximum load at failure.

6- Generally, composite compression and flexural failure modes were observed for the hybrid ECC columns with eccentric loading incorporated multi cracks localized approximately at mid-height of the column.

\begin{tabular}{|c|c|c|c|c|c|c|}
\hline \multirow{2}{*}{\multicolumn{2}{|c|}{ No. Sample }} & \multirow{2}{*}{$\begin{array}{l}\text { Experimentally } \\
\text { measured load } \\
\text { carrying capacity, } \\
\text { (MPa) }\end{array}$} & \multicolumn{4}{|c|}{ Direct calculation from reciprocal method Suggested modification for the calculation from reciprocal method } \\
\hline & & & $\begin{array}{l}\text { Calculated load carrying } \\
\text { capacity using strength } \\
\text { interaction diagram [2]- MPa }\end{array}$ & $\begin{array}{l}\text { Percentage } \\
\text { difference, } \%\end{array}$ & $\begin{array}{l}\text { Calculated load carrying capacity using strength } \\
\text { interaction diagram [2]-MPa }\end{array}$ & $\begin{array}{l}\text { Percentage difference, } \\
\%\end{array}$ \\
\hline 1 & EBe1-0.5 S-0.5 P & 1371 & 1089 & -21 & 1500 & +9 \\
\hline 2 & EBe1-1 S-0.5 P & 1450 & 1089 & -25 & 1500 & +3 \\
\hline 3 & CBe1 & 1094 & 1089 & 000 & 1089 & 0 \\
\hline 4 & EBe2-0.5 S-0.5 P & 813 & 552 & -32 & 827 & +2 \\
\hline 5 & EBe2-1 S-0.5 P & 850 & 552 & -35 & 827 & -3 \\
\hline 6 & EBe2-0 S-0.5 P & 795 & 552 & -31 & 827 & +4 \\
\hline 7 & EBe2-1 S-0 P & 941 & 552 & -41 & 827 & -12 \\
\hline 8 & $\mathrm{CBe} 2$ & 624 & 552 & -12 & 552 & -12 \\
\hline
\end{tabular}

$$
\frac{1}{P_{n}}=\frac{1}{P_{n x 0}}+\frac{1}{P_{n y 0}}-\frac{1}{P_{0}}
$$

Where $P_{n}$ is the approximate value of ultimate load in biaxial bending with eccentricities $e_{x}$ and $e_{y} ; P_{n x 0}$ is the ultimate load when only eccentricity $e_{y}$ is present; $P_{n y 0}$ is the ultimate load when only eccentricity $e_{x}$ is present; and $P_{0}$ is the ultimate load for concentrically loaded column. In this study, uniaxial loads were adopted, so $P_{n y 0}$ was only available for estimation. Based upon the column strength interaction diagram for the rectangular section with bars on end faces and $\gamma=0.45$ and 0.6 , the predicted values of load carrying capacities for the eccentric loading columns against their experimentally measured results are presented in Table 3. It can be seen that the predicted values of load carrying capacities for both of concrete columns (i.e. $\mathrm{CBe} 1$ and $\mathrm{CBe} 2$ ) were close to those measured values. On the other hand, none of the predicated values of ECC columns was in agreement with their corresponding experimental result. In order to improve the accurate of calculations, a modified technique was suggested to calculate the load carrying capacity from the reciprocal method. This was throughout incorporating the fibre ratio in the term of A_stbh. The latter is one of the main components of the interaction diagram. This in turn

\section{REFERENCES}

1. Adnan Al-Sibahy, Behaviour of Reinforced Concrete Columns Strengthened with Ferrocement under Compression Conditions: Experimental Approach, World Journal of Engineering and Technology, 2016, 4, 608-622.

2. Nilson, A.H. and Darwin, D. (1997) Design of Concrete Structures. 5th Edition, McGraw-Hill.

3. Li, J.B., Gong, J.X. and Wang, L.C. (2009) Seismic Behavior of CorrosionDamaged Reinforced Concrete Columns Strengthened Using Combined Carbon Fiber-Reinforced Polymer and Steel Jacket. Construction and Building Materials , 23, 2653-2663.

4. Zhou, X.H. and Liu, J.P. (2010) Seismic Behavior and Strength of Tubed Steel Reinforced Concrete (SRC) Short Columns. Journal of Constructional Steel Research, 66, 885-896. http://dx.doi.org/10.1016/j.jcsr.2010.01.020.

5. Polies, W., Ghrib, F. and Sennah, K. (2010) Rehabilitation of Interior Reinforced Concrete Slab-Column Connections Using CFRP Sheets. Construction and Building Materials , 24, 1272-1285. http://dx.doi.org/10.1016/j.conbuildmat.2009.12.008. 
6. J. Mater, Engineering Cementitious Composites for Structural Applications, Civ. Eng. 1998.10:66-69.7. Michael D. Lepech , Victor C. Li., Application of ECC for bridge deck link slabs, Materials and Structures (2009) 42:1185-1195. 8. Jun Zhang, Christopher K.Y. Leung, Yuan Gao, Simulation of crack propagation of fiber reinforced cementitious composite under direct tension, Engineering Fracture Mechanics 78 (2011) 2439-2454.

9. Yixin Chen, Jing Yu, Christopher K.Y. Leung, Use of high strength StrainHardening Cementitious Composites for flexural repair of concrete structures with significant steel corrosion, Construction and Building Materials 167 (2018) 325-337.

10. Fang Yuan, et. al., Mechanical Behaviors of Steel Reinforced ECC or ECC/Concrete Composite Beams under Reversed Cyclic Loading, DOI: 10.1061/(ASCE)MT.1943-5533.0000935.

11. Jiajia Zhou, et. al., Mechanical Behavior of Fiber Reinforced Engineered Cementitious Composites in Uniaxial Compression, Journal of Materials in Civil Engineering, doi:10.1061/(ASCE)MT.1943-5533.0001034.

12. Fang Yuan, et. al., Elastoplastic time history analysis of reinforced engineered cementitious composite or engineered cementitious compositeconcrete composite frame under earthquake action, Advances in Structural Engineering 1-13, 2016.
13. Zhong Tao, et. al., Experimental behaviour of concrete-filled stiffened thinwalled steel tubular columns, Thin-Walled Structures 45 (2007) 517-527.

14. Chung-Chan Hung, Fuo-Yao Hu, Behavior of high-strength concrete slender columns strengthened with steel fibers under concentric axial loading, Construction and Building Materials 175 (2018) 422-433.

15. Fang Yuan, et. al., Behaviors of steel-reinforced ECC columns under eccentric compression, Construction and Building Materials 185 (2018) 402 413.

16. EN BS 197-1. Cement, Part 1: Compositions, specification and conformity criteria for common cements. British Standards; 2000.

17. EN BS 882.1992: Specification for aggregate from natural sources for concrete. British Standards; 1992.

18. BS EN 934-2: Admixtures for concrete, mortar and grout, part 2: concrete admixtures - definitions, requirements, conformity, marking and labelling. BSI, 2009, London, UK.

19. ACI 318M-11 Code, Building Code Requirements for Structural Concrete (ACI 318M-11), ACI Committee 318, American Concrete Institute, 2011.

20. BS EN 12390-2. Making and curing specimens for strength test. British Standards, 2009. 